\title{
Determination of the Current Phase of the Credit Cycle in Emerging Markets ${ }^{1}$
}

Elena Deryugina, Bank of Russia

DeryuginaEB@cbr.ru

Alexey Ponomarenko, Bank of Russia

PonomarenkoAA@cbr.ru

We test the ability of early warning indicators that appear in the literature to predict credit cycle peaks in a cross-section of emerging markets, verifying our findings by cross-sectional validation. Our results confirm that the standard credit gap indicator performs satisfactorily. In fact, we find that, in emerging market economies, it seems rather difficult to outperform this indicator by means of augmented multivariate models. Nevertheless, we have found that the robustness of real-time credit cycle determination may potentially be improved (although with a risk of overfitting the data) by simultaneously monitoring GDP growth, banks' non-core liabilities, the financial sector's value added and (to a lesser extent) the change in the debt service ratio.

Keywords: credit cycle, countercyclical capital buffers, early warning indicators, emerging markets

JEL Codes: E37, E44, E51

\begin{abstract}
Citation: Deryugina, E. and Ponomarenko, A. (2019). Determination of the Current Phase of the Credit Cycle in Emerging Markets. Russian Journal of Money and Finance, 78(2), pp. 28-42.
\end{abstract}

doi: $10.31477 /$ rjmf.201902.28

\section{Introduction}

There are good reasons to believe that correctly determining the current phase of the credit cycle is essential for efficient policymaking. Borio and Lowe $(2002,2004)$ document the usefulness of the credit gap (the gap between the credit-to-GDP ratio and its long-term trend) as a good early warning indicator for banking crises. The association of general macroeconomic and

\footnotetext{
${ }^{1}$ The views expressed in this paper are those of the authors and do not necessarily represent the position of the Bank of Russia. We are grateful to Sergei Seleznev and participants in seminars at the Bank of Russia, the Bank for International Settlements, and the 36th International Symposium on Forecasting for their helpful comments and suggestions.
} 
financial developments with credit boom/bust cycles is also examined closely in a number of studies (see e.g. Mendoza and Terrones, 2012). Importantly, the close link between credit cycle indicators and credit losses is well documented (Dell'Ariccia et al., 2012; Geršl and Seidler, 2015; Jokivuolle et al., 2015).

The debate about appropriate measurement of the credit cycle intensified after Basel III introduced the credit gap as a measure of the credit cycle phase and a guide for setting countercyclical capital buffers (CCB) (Basel Committee on Banking Supervision, 2010). Although the general usefulness of this indicator is confirmed for a broad array of countries and a long time span that includes the most recent crisis, criticism of this choice appears in the literature, focusing on several areas (see Drehmann and Tsatsaronis, 2014, for a summary). The first strand of these arguments is related to the ultimate relevance of the credit gap indicator as a measure of disequilibrium. In this paper, however, we will not address this issue, concentrating instead on realtime measurement of the credit gap (i.e. the end-point problem discussed by Edge and Meisenzahl, 2011).

It is argued that the reliability of the credit gap indicator may be improved when it is used in combination with alternative indicators in an early warning indicator system (EWI) set-up. Interest in such supplementary indicators is also driven by demand for a system that could provide a signal early enough to account for the 12-month implementation period for raising the capital buffers specified in the Capital Requirements Directive IV regulation. The literature on such EWIs developed for advanced countries is ample (see e.g. Detken et al., 2014, and Kalatie et al., 2015, for a comprehensive review) but noticeably scarcer for emerging markets. ${ }^{2}$ The aim of this paper is to examine the applicability of the EWI approach to augmenting the credit gap indicator as a guide for setting countercyclical capital buffers specifically for emerging market economies. We reiterate that our focus is not on studying whether credit cycle indicators are in principle useful for policymaking. Instead we look for methods that could help to increase the reliability of credit cycle measures in real time and to predict their future developments in a timely manner. ${ }^{3}$

The rest of the paper is structured as follows. Section 2 outlines and implements methods for measuring the credit cycle. Section 3 discusses the selection of early warning indicator variables. Section 4 describes the data set on which we conduct the empirical analysis, comprising a cross-section of emerging market economies. Section 5 presents the models fitted here to predict credit cycle peaks in the emerging market data set. Section 6 concludes.

\footnotetext{
${ }^{2}$ See Guarín et al. (2014) and Valinskytė and Rupeika (2015) for examples. Drehmann and Tsatsaronis (2014) also touch on the performance of the credit gap indicator in emerging markets.

3 This approach is different from the standard credit cycle literature in which EWIs are developed to predict financial crises, but is not uncommon for business cycle analysis (see e.g. Aastveit et al., 2016).
} 


\section{Measuring the credit cycle}

We adopt a standard approach (as in e.g. Mendoza and Terrones, 2012) as our benchmark measure of the credit cycle: we calculate the credit gap by detrending the log of the credit-to-GDP ratio with the two-sided HodrickPrescott filter $(\lambda=400000)$. We define its local maxima (over the 20 -quarter window ${ }^{4}$ ) as peaks of the credit cycle if they exceed the threshold equal to the respective (country-specific) credit gap's 1.5 standard deviation.

The binary variable that is used as the dependent variable for the EWI is subsequently constructed on the basis of the results obtained. For the CCB to be raised before the transition to a contractionary credit cycle phase, the EWI should issue a signal at least one year before the turning point. Our binary variable therefore equals one over the horizon from five to twelve quarters prior to the identified peak.

We also calculate alternative credit cycle measures (see e.g. Claessens et al., 2011; Drehmann et al., 2012) to check the robustness of the benchmark approach. Specifically, we use two alternative methods. The first is simple turning-point analysis (i.e. identifying the local maxima in the level of the credit-to-GDP ratio). The second involves identifying the local maxima of the cumulated credit-toGDP ratio fluctuations with a frequency of 32-120 quarters (isolated via the bandpass filter). We find that ex-post estimates of the credit cycle are not sensitive to this choice and that the binary variables constructed on the basis of alternative approaches are highly correlated (see Table 6 in the Appendix). ${ }^{5}$ We therefore report only the results obtained using the benchmark approach to credit cycle measurement.

\section{Early warning indicator selection}

Our early warning system comprises a set of indicators presumed to be helpful in real-time prediction of the turning points of the ex-post credit gap measure. Naturally, the most obvious choice is the recursively estimated version of the credit gap itself. We also test the performance of the credit-to-GDP ratio in the form of annual growth.

The choice of auxiliary variables is determined by the existing literature. ${ }^{6}$ Borio and Lowe (2002) point out that, for timely identification of financial imbalances, the credit cycle should be analysed in combination with

\footnotetext{
${ }^{4}$ Drehmann et al. (2012) suggest using a 40-quarter window, but this seems irrelevant to our relatively short series: even with this definition, we are only able to analyse at most one turning point for the countries in our cross-section.

${ }^{5}$ Arguably, this may indicate that the identified peaks are well settled and unlikely to be revised as further observations are added to the sample.

${ }^{6}$ Considering that the cross-section of countries and the time sample used in our analysis are deliberately limited, the main objective of this paper is to verify the findings reported for advanced countries rather than suggest novel approaches.
} 
real-sector developments. We therefore include the annual growth of real GDP in our data set.

Drehmann and Juselius (2012) suggest using the debt service ratio (DSR) to identify unbalanced credit developments. We use this indicator in the form of annual changes rather than in levels, as this helps to improve its performance.

Hahm et al. (2013) find that an increase in banks' non-core liabilities (NCL) may also indicate the unsustainability of credit expansion as banks start to rely heavily on wholesale funding. We use banks' foreign liabilities to credit ratio as a proxy for this variable.

Finally, Banbula and Pietrzak (2017) point out that the increased contribution of the financial sector to GDP growth (a proxy for banks' profit indicator) may be linked with excessive risk-taking and therefore may be a good indicator for forecasting financial risks. We use the share of the financial sector valued added in GDP (FSVA) to reflect these developments.

Table 1. Early warning indicators

\begin{tabular}{ll} 
Indicators & Sources \\
\hline GDP & IMF IFS \\
GDP deflator & National statistical agencies' websites \\
\hline Credit (banks' claims on the private domestic sector) & IMF IFS \\
Banks' liabilities to non-residents (NCL) & Central banks' websites \\
\hline DSR & CEIC \\
\hline Financial sector (financial and insurance activities) & BIS \\
value added & Donets and Ponomarenko (2015) \\
\hline
\end{tabular}

The resulting list of variables is presented in Table 1 . The variables were seasonally adjusted by the authors using the X-12 algorithm. All the variables (with the exception of the credit gap) are in deviations from recursively calculated country-specific means. The descriptive statistics and the variables' dynamics around the credit cycle peaks identified are reported in the Appendix (Table 5 and Figure 1).

Admittedly, our data set is lacking potentially useful variables from several notable categories. The most important of these are asset (property) prices, the significance of which for financial imbalance analysis is underscored by Borio and Lowe (2002). This is due to the scarcity of such data for emerging markets. The second set of missing variables is measures of potential mispricing of risk (e.g. financial spreads and VIX indices). These series are also scarce for emerging markets. Furthermore, considering that emerging financial markets are relatively less developed, the informational content of such measures may be limited. Finally, we deliberately do not 
include global (liquidity and market risk) variables in our data set. We already know from existing studies (e.g. Alessi and Detken, 2011) that the global liquidity indicator would have performed exceptionally well in explaining the last wave of boom/bust episodes in 2005-2007. Due to our limited time sample, we deal almost exclusively with this most recent wave (see Section 4). Obviously, a global liquidity measure, calculated based on monetary developments in advanced economies that is not country-specific with regard to the economies in our sample would explain all the boom/bust episodes observed during that period. Although this fact evidently deserves policymakers' attention, it can hardly be considered robust evidence of the predictive power of such an indicator, as few other boom/bust episodes are available for examination. The effect of the global liquidity spill-over may also be captured by the non-core liability variable.

\section{Data}

The composition of our cross-section of emerging market economies is determined by data availability. ${ }^{7}$ Our main data source is the IMF IFS database, although we also use CEIC, the OECD statistical database and national central banks' and statistical agencies' websites (see Table 1 for details). We use the DSR series reported by the BIS if available and the series collected by Donets and Ponomarenko (2015) otherwise. All the series have a quarterly frequency (although occasionally these are interpolated from annual data) and are seasonally adjusted.

We collect data for 25 emerging market economies in total. Our time sample ends in 2015. Accordingly, the dependent binary variable (which precedes the credit cycle peak by 5-12 quarters) may be calculated up to 2012. The explanatory variables are usually available starting from the early 2000s. This gives a time period of about a decade to evaluate our models, which effectively means that we are able to observe one credit cycle peak per country at most. Consequently, our cross-section contains twelve countries that experienced the transition from an expansionary to a contractionary credit cycle phase in 2007-2009, five countries where the transition happened at a different time and eight countries where no credit cycle turning points can be identified (see Table 7 in the Appendix for details).

\footnotetext{
${ }^{7}$ Compiling an appropriate data set is a significant challenge in constructing the early warning indicator system based on panel data. It may seem logical to use a homogeneous cross-section that includes only relevant and similar economies. The caveat here is that it is also desirable to have a data set that is balanced as regards the presence of boom/bust occurrences. For example, if our data set included only Central and Eastern European countries (most of which experienced asset price booms/busts), we would be unable to test the performance of the system in a tranquil environment. We therefore do not limit our cross-section to any particular group of countries and thus include all emerging markets for which adequate data are available.
} 


\section{Empirical analysis}

We evaluate our models following Drehmann and Juselius (2014) using the area under the ROC curve (AUC): a statistical methodology that captures the tradeoff between true positives and false positives for the full range of policymakers' preferences. ${ }^{8}$ As data availability differs for the various explanatory variables, we report the evaluation results for the full (indicator-specific) available time sample as well as for the common time sample.

\subsection{Stand-alone indicators}

We begin by examining individual indicators' performance by means of the 'signalling' approach. This approach assumes an extreme non-linear relationship between the indicator and the event to be predicted and transforms the indicators into binary signals: if a given indicator crosses a critical threshold, it is said to send a signal. The signal is assumed to be issued when the indicator's value exceeds a threshold (the same for all countries) defined in terms of the recursively calculated (country-specific) percentile. We perform variable-specific evaluation of the indicators' performance (in terms of the AUC indicator) for a variety of percentile thresholds. As described in Section 2, we expect the signal to be issued five to twelve quarters before the peak. The results are reported in Table 2 (the actual ROC curves are presented in Figure 2 in the Appendix).

Table 2. Stand-alone indicators' AUC

\begin{tabular}{l|c|c|c|c|c|c} 
& Credit gap & $\begin{array}{c}\text { Credit } \\
\text { growth }\end{array}$ & GDP growth & DSR & NCL & FSVA \\
\hline $\begin{array}{l}\text { Full available } \\
\text { time sample }\end{array}$ & 0.67 & 0.68 & 0.55 & 0.60 & 0.52 & 0.60 \\
\hline $\begin{array}{l}\text { Common } \\
\text { time sample }\end{array}$ & 0.68 & 0.70 & 0.58 & 0.62 & 0.52 & 0.58 \\
\hline
\end{tabular}

We find that the performance of the credit gap indicator (AUC equals 0.68) is similar to the results of the evaluation conducted by Drehmann and Tsatsaronis (2014) for emerging markets at the respective forecast horizon. It is marginally outperformed by the credit growth variable but not by the other auxiliary indicators.

We test the statistical significance of the differences between the AUCs of alternative indicators by means of a bootstrapping approach. Specifically, we generate 5000 datasets by randomly drawing (with replacement) from the original dataset and calculate the distribution of differences in the respective

\footnotetext{
${ }^{8}$ We have examined the models' performance in terms of other measures, such as areas under precision recall curves (recommended by Murphy (2012) for samples with rare true events). Our results seem to be robust to the choice of performance measurement.
} 
AUC measures. We assume that the difference is statistically significant if zero is outside of the $95 \%$ bootstrapped confidence interval derived from the distribution of AUC differences. We find that the AUC obtained using the credit gap is significantly different from the AUCs obtained using all the other alternative indicators, with the exception of the credit growth variable.

\subsection{Discrete choice models}

As the second approach, we set up an early warning indicator system in the form of a discrete choice model using the binary indicator described in Section 2 as a dependent variable. This approach makes use of pooled ${ }^{9}$ probit regression techniques to evaluate an indicator's contribution to predicting a credit cycle peak. This method enables us to take into account correlations between different indicator variables and to evaluate the statistical significance of individual variables. The results are reported in Table 3 (the actual ROC curves of the estimated models are presented in Figure 3 in the Appendix).

Table 3. Probit models

\begin{tabular}{lccc} 
& Model 1 & Model 2 & Model 3 \\
\hline Credit gap & $1.6(3.0)$ & $1.4(3.0)$ & $1.7(3.2)$ \\
\hline Credit growth & $0.0(0.0)$ & - & - \\
\hline GDP growth & $8.1(5.2)$ & $5.7(4.4)$ & $7.6(4.9)$ \\
\hline DSR & $-0.3(-0.1)$ & - & $-5.0(-1.2)$ \\
\hline NCL & $3.1(4.0)$ & $1.9(2.6)$ & $3.1(4.0)$ \\
\hline FSVA & $9.3(1.8)$ & $13.2(2.6)$ & $3.7(0.6)$ \\
\hline DSR ${ }^{\star}$ GDP growth & - & - & $188.1(2.1)$ \\
\hline Credit gap ${ }^{\star}$ FSVA & - & - & $-1.36(-20.6)$ \\
\hline C & $-1.4(-19.6)$ & $-1.32(-21.8)$ & $\mathbf{9 5 9}$ \\
\hline Observations & $\mathbf{9 5 9}$ & $\mathbf{1 0 1 7}$ & $\mathbf{0 . 1 1}$ \\
\hline McFadden $\mathbf{R}^{2}$ & $\mathbf{0 . 1}$ & $\mathbf{0 . 0 7}$ & $\mathbf{0 . 7 6}$ \\
\hline AUC (full time sample) & $\mathbf{0 . 7 4}$ & $\mathbf{0 . 7 1}$ & $\mathbf{0 . 7 6}$ \\
\hline AUC (common time sample) & $\mathbf{0 . 7 4}$ & $\mathbf{0 . 7 4}$ & \\
\hline
\end{tabular}

Note: $\mathrm{z}$-statistics are given in parentheses.

We begin by including all the explanatory variables in the model simultaneously (Model 1). The credit gap is found to be highly statistically significant. Contrary to its performance as a stand-alone indicator, credit growth is not useful in combination with other variables, and nor is the change in the DSR. These variables may be excluded without decreasing the AUC indicator (Model 2). The other three auxiliary variables remain statistically significant.

\footnotetext{
${ }^{9}$ We do not employ fixed-effect probit regressions in our analysis because, as noted by Davis and Karim (2008), this approach would lead to information loss for countries that did not experience a credit cycle peak. In fact, we believe that fixed-effect analysis is irrelevant to our models, as all the explanatory variables are detrended or demeaned.
} 
As pointed out in Borio and Lowe (2004), it may be important to appropriately combine the information contained in the developments of alternative early warning indicators. For example, rapid credit growth may have different implications for the probability of a financial crisis depending on whether it is observed simultaneously with output growth acceleration. We therefore experiment further by considering the bivariate interactions of the variables (Model 3). We find that we may marginally improve the model's performance by interacting the credit gap with the financial sector's value added, and the change in the DSR with GDP growth. ${ }^{10}$

The bootstrap-based statistical tests indicate that the AUC of all the multivariate models is significantly larger than the AUC obtained using the stand-alone credit gap indicator. Moreover, the AUC measures of Models 1 and 2 are statistically indistinguishable but are significantly smaller than the AUC of Model 3.

The fact that the multivariate models are able to outperform the standalone indicators is not unexpected, but there is always a risk that this could be achieved by overfitting the data. Examining the out-of-sample performance of the models may help to assess the seriousness of these concerns. We therefore report the results of conventional cross-validation procedures (see e.g. Murphy, 2012). ${ }^{11}$

We split the data set into five folds; then, for each fold $k \in\{1, \ldots, 5\}$, we estimate our models using all the folds but the $k$-th and test the $k$-th in a round-robin fashion. We then compute the AUC over all the folds (Table 3). We use two alternative methods for determining the composition of each fold. The countries in our cross-section are divided into five regional sub-groups ${ }^{12}$ (as reported in Table 7 in the Appendix). In the first approach, we compose balanced folds by randomly including one country from each region. In the second approach, our folds are exclusively comprised of countries from the same region. Arguably, if the resulting models' performance is worse in the second case (i.e. if replacing the data from neighbouring countries with other data makes the model's parametrisation less appropriate for a given economy), it may indicate heterogeneity among the countries in the cross-section.

In addition to the five-fold approach, we employ the 'leave one out' strategy (i.e. we use the approach on all the data cases except for country $i$ and then test on country $i$ ), which is less demanding but may be preferable for small samples.

\footnotetext{
${ }^{10}$ We presume this finding shows that, by using such interactions, it is possible to distinguish between cases where the credit gap or DSR growth is driven by credit expansion and cases where it is driven by GDP contraction.

${ }^{11}$ The credit peak occurrences appear in one wave, precluding recursive estimation of the models, which may be regarded as another way to examine the problem of overfitting in time series analysis.

12 These are: 1) Eastern Europe (former Soviet Union), 2) Eastern Europe (other), 3) Latin America, 4) Southeast Asia and 5) Other.
} 
Table 4. Cross-validation results (AUC for the common time sample)

\begin{tabular}{l|c|c|c}
\hline Cross-validation method & Model 1 & Model 2 & Model 3 \\
\hline Five-fold (balanced) & 0.63 & 0.67 & 0.66 \\
\hline Five-fold (regional) & 0.65 & 0.69 & 0.7 \\
\hline Leave one out & 0.64 & 0.68 & 0.68 \\
\hline
\end{tabular}

The results indicate that, although the out-of-sample performance of the multivariate models is still satisfactory, they do not outperform the best standalone indicators (credit gap and credit growth). This suggests that the better insample performance of multivariate models may at least partially be associated with overfitting of the data. Interestingly, it seems that, in this case, using models parametrised exclusively on the basis of data observed in countries from different regions is not particularly problematic.

\section{Conclusion}

Basel III uses the gap between the credit-to-GDP ratio and its long-term trend as a measure of the credit cycle phase and a guide for setting countercyclical capital buffers. Criticism of this choice centres on several areas. The main concerns are practical measurement and end-point problems. Recent studies find that several indicators that do not require detrending may be successful in identifying the build-up of financial imbalances. Interest in such supplementary indicators is also driven by demand for a system that could provide a signal early enough to account for the 12-month implementation period for raising the capital buffers specified in the Capital Requirements Directive IV regulation.

We contribute to the existing literature in several ways. Firstly, we concentrate on the applicability of our analysis to a cross-section consisting exclusively of emerging market economies ( 25 in total). The sample obtained is large enough for interpretable econometric analysis, although its informational content is limited since, for the most part, only one wave of credit cycle peaks (the most recent) can be analysed. Therefore, in order to verify our findings, we apply the cross-sectional validation approach, which is rarely used in the literature.

Our results confirm that the standard credit gap indicator performs satisfactorily in real time. In fact, we find that, in emerging market economies, it seems rather difficult to outperform this indicator by means of augmented multivariate models. This is our main finding. Nevertheless, we also report several indicators that may be useful in real-time identification of the credit cycle's phase. Specifically, the growth rates of the credit-to-GDP ratio perform equally well as a stand-alone indicator, although there is no gain in combining them with the gap measure. We argue that credit growth is more likely to be unsustainable if accompanied by higher real growth rates. The robustness 
of real-time credit cycle determination may also be improved by monitoring banks' non-core liabilities, the financial sector's value added and (to a lesser extent) the change in the DSR by means of a multivariate discrete choice model (although with a risk of overfitting the data).

\section{References}

Aastveit, K. A., Jore, A. S. and Ravazzolo, F. (2016). Identification and Real-Time Forecasting of Norwegian Business Cycles. International Journal of Forecasting, 32(2), pp. 283-292.

Alessi, L. and Detken, C. (2011). Quasi Real Time Early Warning Indicators for Costly Asset Price Boom/Bust Cycles: A Role for Global Liquidity. European Journal of Political Economy, 27(3), pp. 520-533.

Banbula, P. and Pietrzak, M. (2017). Early Warning Models of Banking Crises Applicable to Non-Crisis Countries. NBP Working Paper, N 257.

Basel Committee on Banking Supervision (2010). Guidance for National Authorities Operating the Countercyclical Capital Buffer.

Borio, C. and Lowe, P. (2002). Asset Prices, Financial and Monetary Stability: Exploring the Nexus. BIS Working Paper, N 114.

Borio, C. and Lowe, P. (2004). Securing Sustainable Price Stability: Should Credit Come Back from the Wilderness? BIS Working Paper, N 157.

Claessens, S., Kose, M. A. and Terrones, M. E. (2011). Financial Cycles: What? How? When? IMF Working Paper, N 76.

Davis, E.P. and Karim, D. (2008). Comparing Early Warning Systems for Banking Crises. Journal of Financial Stability, 4(2), pp. 89-120.

Dell'Ariccia, G., Igan, D., Laeven, L., Tong, H., Bakker, B. and Vandenbussche, J. (2012). Policies for Macrofinancial Stability: How to Deal with Credit Booms. IMF Staff Discussion Note, N 6.

Detken, C., Weeken, O., Alessi, L., Bonfm, D., Boucinha, M. M., Castro, C., Frontczak, S., Giordana, G., Giese, J., Jahn, N., Kakes, J., Klaus, B., Lang, J., Puzanova, N. and Welz, P. (2014). Operationalising the Countercyclical Capital Buffer: Indicator Selection, Threshold Identification and Calibration Options. ERSB Occasional Paper Series, N 5.

Donets, S. and Ponomarenko, A. (2015). Measuring Debt Burden. Bank of Russia Working Paper Series, N 5.

Drehmann, M., Borio, C. and Tsatsaronis, K. (2012). Characterising the Financial Cycle: Don't Lose Sight of the Medium Term! BIS Working Paper, N 380.

Drehmann, M. and Juselius, M. (2012). Do Debt Service Costs Affect Macroeconomic and Financial Stability? BIS Quarterly Review, September, pp. 21-34.

Drehmann, M. and Juselius, M. (2014). Evaluating Early Warning Indicators of Banking Crises: Satisfying Policy Requirements. International Journal of Forecasting, 30(3), pp. 759-780. 
Drehmann, M. and Tsatsaronis, K. (2014). The Credit-to-GDP Gap and Countercyclical Capital Buffers: Questions and Answers. BIS Quarterly Review, March, pp. 55-73.

Edge, R. and Meisenzahl, R. (2011). The Unreliability of Credit-to-GDP Ratio Gaps in Real-Time: Implications for Countercyclical Capital Buffers. International Journal of Central Banking, 7(4), pp. 261-298.

Geršl, A. and Seidler, J. (2015). Countercyclical Capital Buffers and Credit-to-GDP Gaps: Simulation for Central, Eastern, and Southeastern Europe. Eastern European Economics, 53(6), pp. 439-465.

Guarín, A., González, A., Skandalis, D. and Sánchez, D. (2014). An Early Warning Model for Predicting Credit Booms Using Macroeconomic Aggregates. Ensayos sobre Política Económica, 32(73), pp. 77-86.

Hahm, J., Shin, H. S. and Shin, K. (2013). Noncore Bank Liabilities and Financial Vulnerability. Journal of Money, Credit and Banking, 45(1), pp. 3-36.

Jokivuolle, E., Pesola, J. and Viren, M. (2015). Why is Credit-to-GDP a Good Measure for Setting Countercyclical Capital Buffers. Journal of Financial Stability, 18(C), pp. 117-126.

Kalatie, S., Laakkonen, H. and Tölö, E. (2015). Indicators Used in Setting the Countercyclical Capital Buffer. Bank of Finland Research Discussion Papers, N 8.

Mendoza, E. G. and Terrones, M. E. (2012). An Anatomy of Credit Booms and their Demise. NBER Working Paper, N 18379.

Murphy, K. P. (2012). Machine Learning: A Probabilistic Perspective. Cambridge, Massachusetts: MIT Press.

Valinskytė, N. and Rupeika, G. (2015). Leading Indicators for the Countercyclical Capital Buffer in Lithuania. Lietuvos Bankas Occasional Papers Series, N 4. 


\section{APPENDIX}

Table 5. Descriptive statistics of the variables

\begin{tabular}{lcccc}
\multicolumn{1}{c}{ Variable } & Mean & Standard Deviation & Minimum & Maximum \\
\hline Credit gap & -0.02 & 0.17 & -0.82 & 0.35 \\
\hline DSR & 0.00 & 0.02 & -0.15 & 0.08 \\
\hline NCL & 0.00 & 0.08 & -0.38 & 0.29 \\
\hline Credit growth & -0.10 & 0.38 & -3.36 & 0.46 \\
\hline GDP growth & 0.00 & 0.04 & -0.24 & 0.25 \\
\hline FSVA & 0.00 & 0.01 & -0.05 & 0.06 \\
\hline
\end{tabular}

Table 6. Concordance between alternative binary variables

(fraction of time for which two series are equal)

\begin{tabular}{lc|c|c} 
& Benchmark & Turning point analysis & $\begin{array}{c}\text { Frequency-based } \\
\text { filter analysis }\end{array}$ \\
\hline Benchmark & 1 & 0.886 & 0.818 \\
\hline Turning point analysis & 0.886 & 1 & 0.826 \\
\hline Frequency-based filter analysis & 0.818 & 0.826 & 1 \\
\hline
\end{tabular}

Table 7. Cross-section of countries

\begin{tabular}{|c|c|c|c|}
\hline Countries & $\begin{array}{c}\text { Time sample (available for all } \\
\text { indicators) }\end{array}$ & Credit cycle peaks & Regional sub-group \\
\hline Belarus & 2005Q1-2012Q2 & 2010Q1 & I \\
\hline Brazil & 2001Q4-2012Q2 & - & III \\
\hline Chile & 2003Q1-2012Q2 & 2008Q4 & III \\
\hline China (Hong Kong) & 2000Q1-2012Q2 & - & IV \\
\hline China & 2000Q1-2012Q2 & 2003Q2 & IV \\
\hline Colombia & 2001Q4-2012Q2 & - & III \\
\hline Czech Republic & 2001Q1-2012Q2 & - & II \\
\hline Estonia & 2004Q4-2012Q2 & 2009Q2 & I \\
\hline Georgia & 2001Q4-2012Q2 & 2008Q4 & I \\
\hline Hungary & 2001Q1-2012Q2 & 2009Q1 & II \\
\hline India & 2004Q2-2012Q2 & 2006Q4 & $\mathrm{V}$ \\
\hline Indonesia & 2001Q4-2012Q2 & 2005Q3 & IV \\
\hline Kazakhstan & 2001Q4-2012Q2 & 2007Q3 & $\mathrm{V}$ \\
\hline Korea & 2001Q4-2012Q2 & 2009Q1 & IV \\
\hline Lithuania & 2004Q4-2012Q2 & 2009Q3 & I \\
\hline Macedonia & 2006Q4-2012Q2 & 2008Q4 & II \\
\hline Malaysia & 2001Q4-2012Q2 & - & IV \\
\hline Mexico & 2001Q4-2012Q2 & - & III \\
\hline Moldova & 2001Q4-2012Q2 & 2008Q2 & I \\
\hline Poland & 2004Q1-2012Q2 & 2009Q1 & II \\
\hline Russia & 2003Q1-2012Q2 & 2009Q1 & $\mathrm{V}$ \\
\hline Slovenia & 2005Q4-2012Q2 & - & II \\
\hline South Africa & 2001Q4-2012Q2 & 2007Q4 & V \\
\hline Thailand & 2001Q4-2012Q2 & - & IV \\
\hline Turkey & 2002Q1-2012Q2 & - & $\mathrm{V}$ \\
\hline
\end{tabular}


Figure 1. Early warning indicators
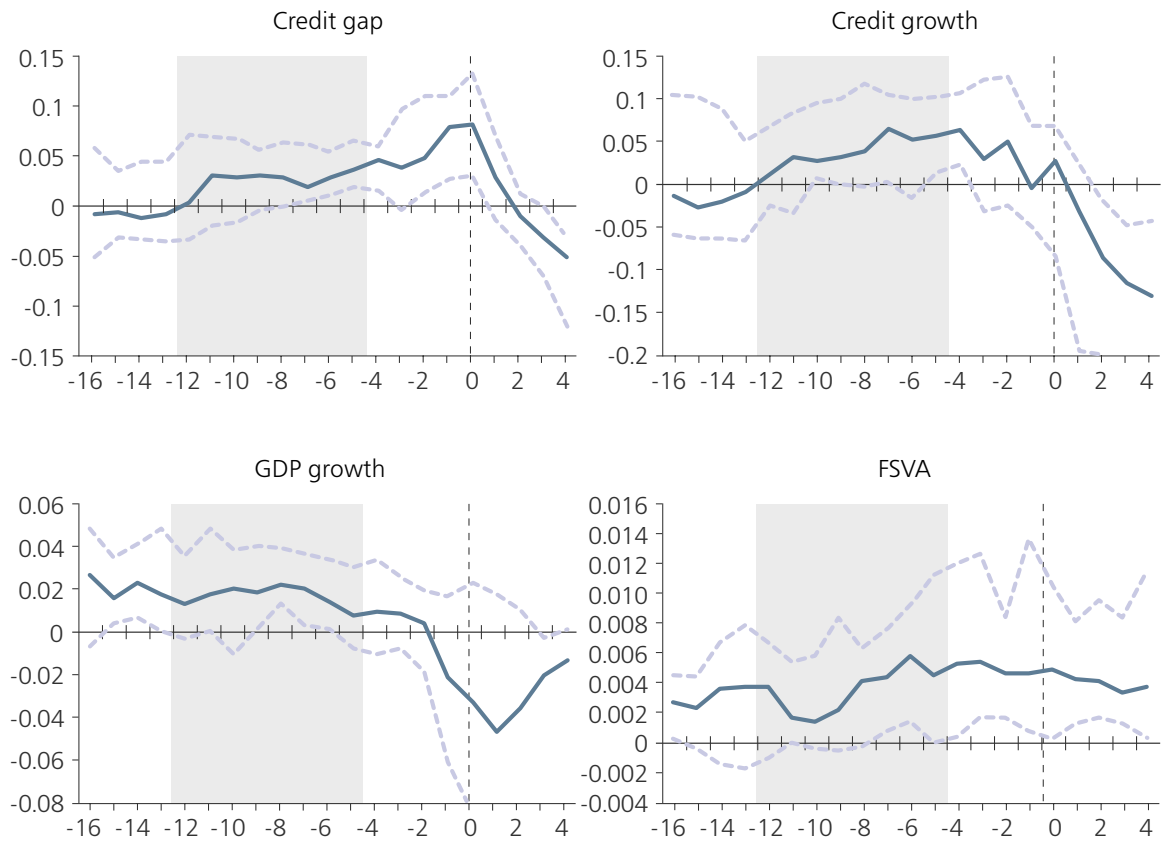

DSR

$\mathrm{NCL}$
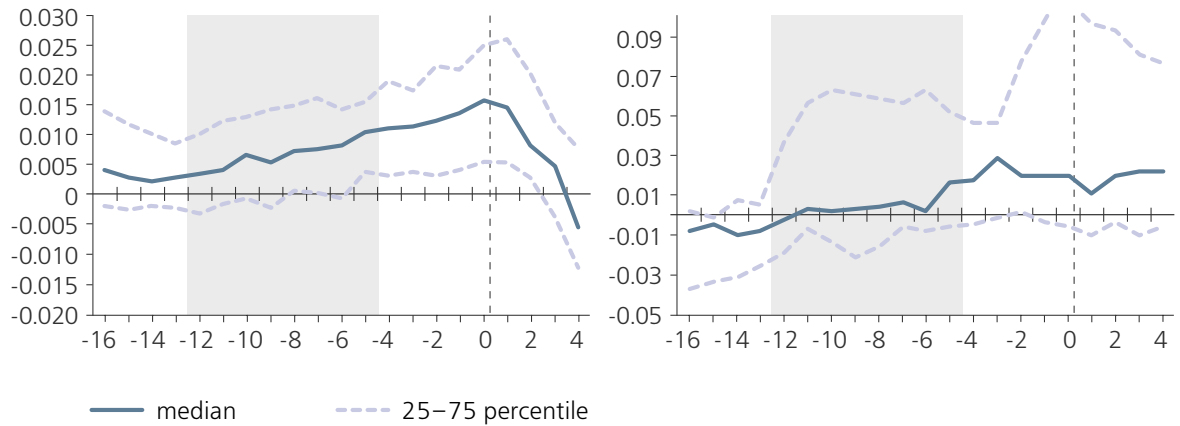

Note: the figure shows variables' dynamics around (in quarters) the identified credit cycle peaks (denoted by 0 on $\mathrm{x}$-axis). 
Figure 2. Stand-alone indicators' ROC curves
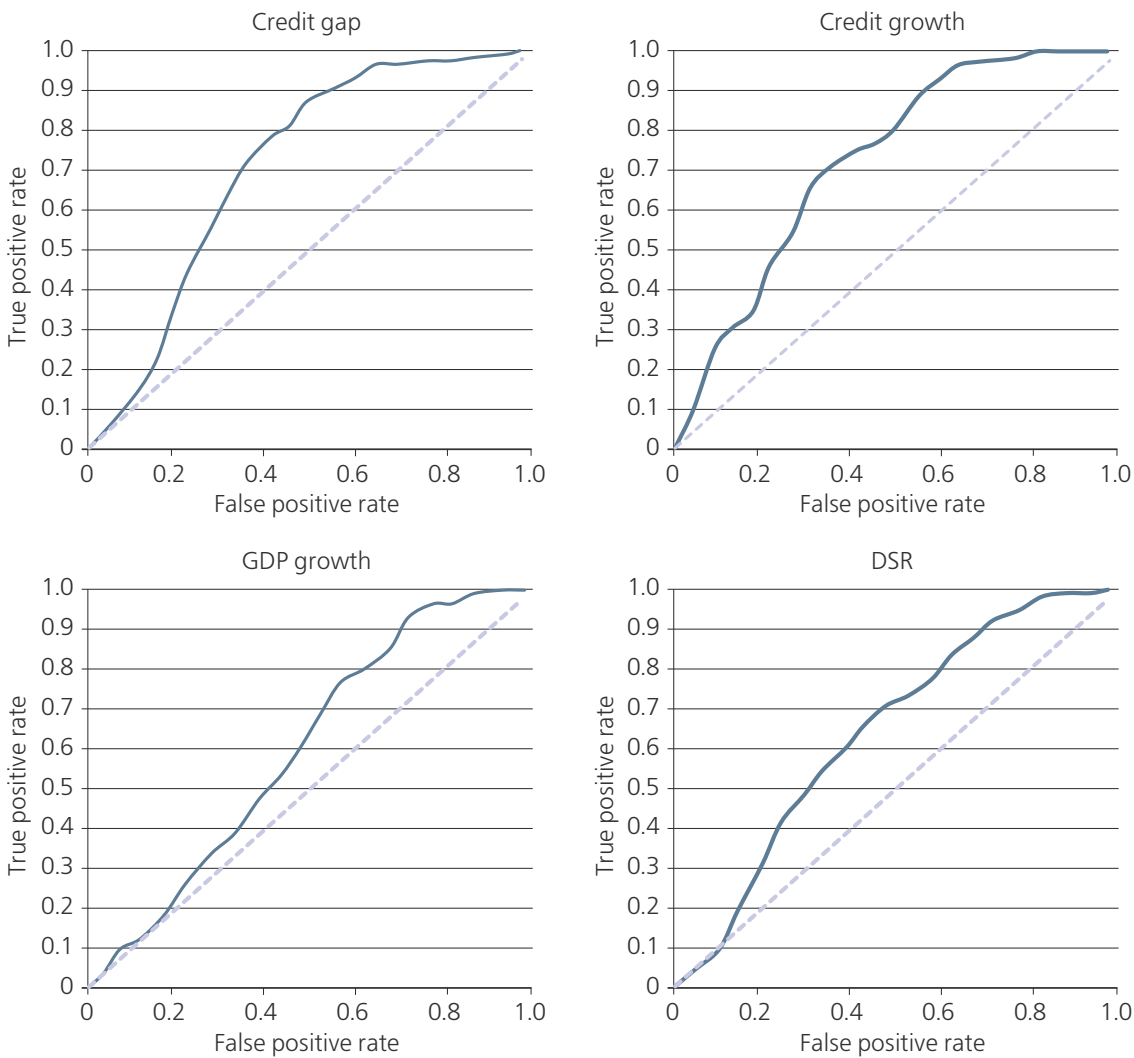

$\mathrm{NCL}$

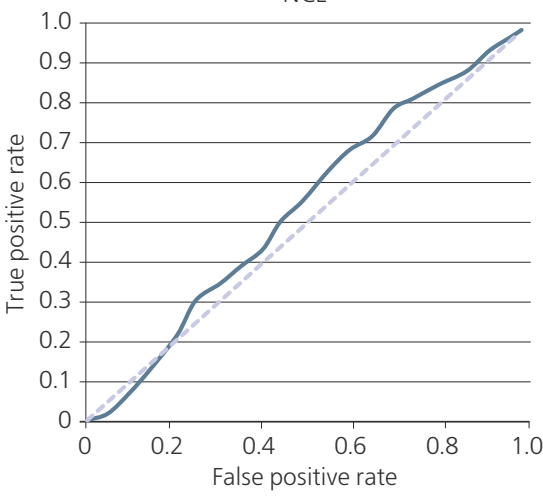

FSVA

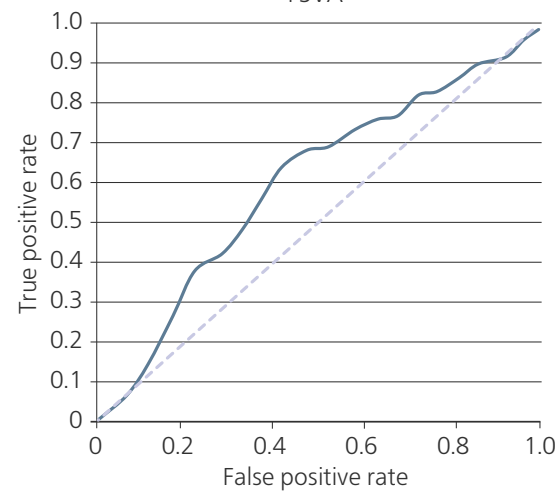


Figure 3. Probit models' ROC curves

Model 1

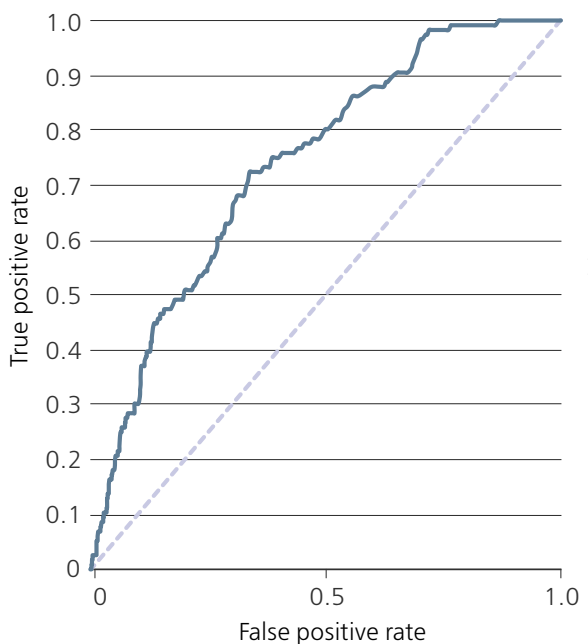

Model 2

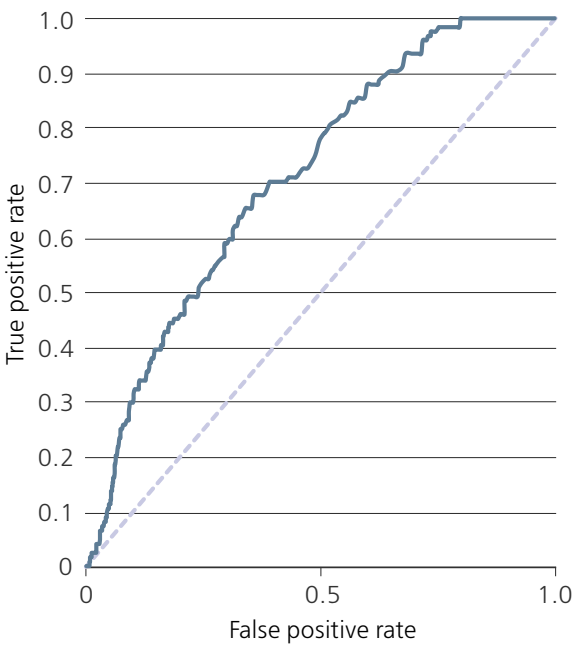

Model 3

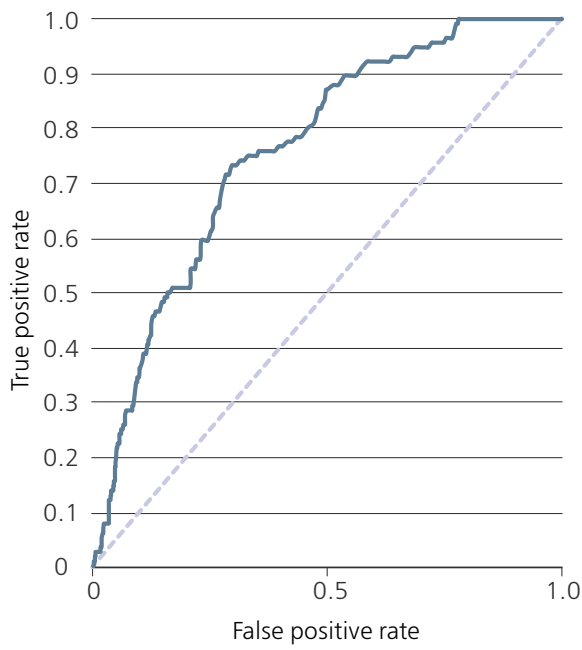

